\title{
Balanced Study
}

National Cancer Institute

\section{Source}

National Cancer Institute. Balanced Study. NCI Thesaurus. Code C142398.

A study in which there is an equal distribution of individuals across groups or arms. 